\title{
Analyse des connaissances endogènes et des déterminants de la production de la patate douce [Ipomoea batatas (L.)], une culture à haute valeur socioculturelle et économique au Bénin
}

\author{
Arsène M. DOUSSOH ${ }^{1 *}$, Justine S. DANGOU ${ }^{2}$, Serge S. HOUEDJISSIN ${ }^{1}$, \\ Armel K. ASSOGBA ${ }^{1}$ et Corneille AHANHANZO ${ }^{1}$
}
${ }^{1}$ Laboratoire Central de Biotechnologies Végétales et d'Amélioration des plantes, Département de Génétique et des Biotechnologies de la Faculté des Sciences et Techniques de l'Université d'Abomey-Calavi, 01 BP 526,
Cotonou, Bénin.
${ }^{2}$ Laboratoire d'Etude et de Recherche en Chimie Appliquée, Ecole Polytechnique d'Abomey-Calavi de
l'Université d'Abomey-Calavi, 01 BP 2009, Cotonou, Bénin.
*Auteur correspondant ; E-mail : dousserne@yahoo.fr; Tel : +229 97328559.

\section{RESUME}

La patate douce est une culture négligée alors que sa contribution dans la sécurité alimentaire est importante au Bénin. Ce travail a permis d'évaluer les connaissances paysannes sur la diversité, les contraintes de production, les pratiques agricoles de conservation des tubercules et de gestion du système semencier de la patate à travers 35 villages du Sud-Bénin. La méthodologie a consisté en une recherche participative par des entretiens individuels et de groupe. Les résultats obtenus ont permis de recenser 87 variétés locales sous réserve de synonymie. Le nombre de variétés locales varie de 1 à 12 par village. La plupart des producteurs utilisent la forme des feuilles et la couleur de la peau des tubercules pour reconnaître les variétés. Des réponses obtenues, le fort taux de multiplication (19,32\%), la précocité $(15,07 \%)$, la valeur marchande élevée $(16,13 \%)$ constituent des critères de sélection des variétés destinées à la production. De même, 7 contraintes majeures parmi lesquelles l'insuffisance de boutures de variétés performantes $(19,73 \%)$, la rareté des pluies $(19,46 \%)$, la baisse de productivité $(19,10 \%)$, ont été identifiées et entravent la production de la patate douce. Par ailleurs, les producteurs ne disposent d'aucune mesure de conservation durable des tubercules. Le système semencier reste traditionnel.

(C) 2016 International Formulae Group. All rights reserved.

Mots clés : Ipomoea batatas, Diversité variétale, Critères de préférences, Contraintes, Bénin.

\section{Analysis of endogenous knowledge and determinants of sweet potato production [Ipomoea batatas (L.)], a high socio-cultural and economic value culture in Benin}

\section{ABSTRACT}

The sweet potato is a neglected crop while its contribution in food security is an important in Benin. This work has assessed endogenous knowledge on diversity, production constraints, farming pratices of tubers 
conservations and seed system management of sweet potato through 35 villages of South-Benin. The methodological approach consisted of a participative research for individual and group interviews. The results have identified 87 local varieties under reservation of synonymy. The number of local varieties varies from 1 to 12 per village. Most of farmers use leaf shape and color of the skin of the tubers to recognize varieties. This answers obtained, high multiplication rate $(19.32 \%)$, precocity $(15.07 \%)$, high market value $(16.13 \%)$ are varieties selection criteria for production. Likewise, 7 major constraints among inadequate performance varieties stems (19.73\%), lack of rain (19.46\%), decreased productivity (19.10\%) have been identified and inhibit the production of sweet potatoes. Moreover, producers have no lasting measure to preserve durably tubers. The stem system is traditional.

(C) 2016 International Formulae Group. All rights reserved.

Keywords: Ipomoea batatas, Varietal diversity, Preference criteria, Constraints, Benin.

\section{INTRODUCTION}

La patate douce Ipomoea batatas (L.) de la famille des Convolvulacées fait partie des plantes à racines et tubercules consommées par plus de deux milliards de personnes dans le monde (Lebot et al., 2009). Ses tubercules présentent une richesse en vitamines $\mathrm{A}$ et $\mathrm{C}$, en fer, en calcium et en acides aminés (Tumwegamire et al., 2011; Sanoussi et al., 2016). En dehors de la consommation humaine, les tubercules et les feuilles sont utilisés dans l'alimentation animale (Owori et al., 2007). Dans l'industrie, les tubercules servent à la production d'amidon (Triqui et al., 2009), de carburant, d'alcool et d'acide acétique (Romuald et al., 2013). La production mondiale annuelle des tubercules de patate douce est estimée à 104 millions de tonnes et la culture se fait dans 114 pays à travers le monde (FAO, 2013 ; Khoury et al., 2015). En Afrique, la production est estimée à 20 millions de tonnes ; elle est de 62000 tonnes au Bénin (FAO, 2013). $\mathrm{La}$ patate douce présente des capacités agronomiques intéressantes telles que la bonne productivité, le cycle de production plus ou moins court, une large adaptation climatique et édaphique de la plupart des variétés. Ceci représente des atouts majeurs pour faire face au défi de la sécurité alimentaire dans le contexte des changements climatiques (Glato et al., 2014). En Afrique Sub-sahérienne, la culture de la patate se fait en général, sur de petites superficies plus ou moins fertiles avec peu d'intrants et aboutit à des rendements relativement bon (Khoury et al., 2015).

$\mathrm{Au}$ Bénin, la patate douce est consommée sous forme cuite ou frite et est faiblement transformée. Elle est utilisée surtout en période de soudure et est capable de jouer un rôle intéressant dans la lutte contre la malnutrition chez les enfants (surtout les variétés à chair colorée généralement riche en $\beta$-Carotène, précurseur de vitamine A) (Sanoussi et al., 2013).

Malgré ces importances socioculturelles et économiques, force est de constater que la patate douce fait partie des espèces négligées en matière de recherche au Bénin et est sous utilisée (Dansi et al., 2012). De même, sa production faible est confrontée à de nombreuses contraintes biotiques et abiotiques dont l'irrégularité des pluies, l'absence ou l'insuffisance de variétés performantes limitant sa production, l'indisponibilité de boutures ou lianes pour une production à grande échelle, la sensibilité de certaines variétés aux attaques parasitaires (Adégbola, 2003 ; Zinsou et al., 2010). Des travaux de recherches sur la caractérisation agro morphologique, biochimique des cultivars locaux de patate douce et la valorisation des tubercules par la fabrication de farines infantiles ont été 
menés ces trois dernières années (Sanoussi et al., 2013 ; 2016). Ces travaux ont montré l'existence d'une perte de diversité liée à la disparition de quelques variétés locales. Cependant, certains aspects importants pour mieux cerner l'état actuel de la diversité en vue d'une meilleure conservation de la patate douce n'ont pas été pris en compte. Les critères paysans de reconnaissance et de préférence variétale, les techniques locales de conservation des cultivars ou leurs boutures pour une nouvelle production restent peu connus.

Le présent travail vise à étudier les connaissances endogènes et les déterminants de la production de la patate douce au Bénin. De façon spécifique, il s'agit: (a) d'inventorier les variétés locales utilisées ; (b) d'identifier les critères clés de reconnaissance variétale et les critères de préférence paysans; (c) de déterminer par ordre d'importance les contraintes liées à la production de la patate douce dans la zone d'étude et (d) d'analyser les pratiques agricoles sur les techniques de conservation des tubercules et de gestion des semences.

\section{MATERIEL ET METHODES Milieu d'étude}

Les études ont été conduites au Sud du Bénin localisé entre les parallèles $6^{\circ} 15^{\prime}$ et $7^{\circ} 30^{\prime}$ de latitudes Nord et les méridiens $1^{\circ} 52^{\prime}$ et $2^{\circ} 36^{\prime}$ de longitudes Est. Avec une superficie de $17.019 \mathrm{~km}^{2}$, il est soumis à un climat subéquatorial caractérisé par deux saisons pluvieuses alternées par deux saisons sèches (Akoègninou et al., 2006). La pluviométrie se situe entre $1100 \mathrm{~mm}$ et 1400 $\mathrm{mm}$ de pluie. La température varie entre $26{ }^{\circ} \mathrm{C}$ et $28^{\circ} \mathrm{C}$. Le sol est variable depuis le type sableux jusqu'à la terre de barre en passant par les vertisols. La population compte 4.592.752 habitants selon l'INSAE (Institut National de la Statistique et de l'Analyse Economique). L'agriculture est la première activité exercée suivie secondairement d'autres activités comme l'élevage et la pèche.
La zone d'étude comporte six (6) départements et regroupe (15) communes (Figure 1). Les groupes socio-culturels Fon, Adja, Ouémin, Holli, Sahoué, Aïzo et Nago ont été majoritairement les plus rencontrés.

\section{Critères de choix des sites et méthodologie de collecte de données}

Trente-cinq (35) villages (Tableau 1) ont été sélectionnés sur la base de production de patate douce après des enquêtes réalisées auprès des structures déconcentrées du Ministère de l'Agriculture, de l'Elevage et de la Pêche (MAEP) et des données de la FAO. Les données de prospection ont été collectées suivant une approche de recherche participative en groupe ou individuellement à la maison ou dans les champs entre septembre 2015 à février 2016 auprès de producteurs des deux sexes (Orobiyi et al., 2013). Les producteurs ont été identifiés grâce à l'aide des chefs villages ou des agents du Secteur Communal de Développement Agricole (SCDA). Le nombre de producteurs enquêtés par village varie de onze (11) à vingt-trois (23). Des informations telles que les contraintes de production, les critères de préférence et de reconnaissance variétale ont été prises en compte par groupe. Sur le plan individuel, les données relatives aux aspects sociodémographiques (âge, taille du ménage, sexe, groupe socio-culturel), le nombre de variétés locales maintenues par ménage et la fréquence de production, les critères de reconnaissance variétale, le système semencier, les techniques de conservation des tubercules et des boutures ont été collectées. Dans chaque village, des échantillons de boutures ou de tubercules des cultivars disponibles provenant du champ ont été collectés.

\section{Analyse statistique}

Les données ont été analysées par la statistique descriptive. Le nombre moyen de variétés locales par département, par commune et par village a été déterminé et les 
fréquences de certaines variétés locales dans la zone d'étude ont été calculées pour évaluer l'étendue de leur distribution. Les moyennes des fréquences des critères de reconnaissance et de préférence variétale ont été calculées pour identifier les critères les plus utilisés dans la zone d'étude. Les contraintes liées à la production de la patate douce ont été identifiées par département et leurs fréquences ont été calculées. Le test de chi 2 de Pearson a été utilisé pour évaluer la variabilité des critères entre groupes socio-ethniques et départements. Les différents résultats obtenus ont été représentés sous forme de graphes, tableaux et figures. Les logiciels SPHINX et MINITAB 14 ont été utilisés pour réaliser l'analyse des données.

\section{RESULTATS \\ Caractéristiques sociodémographiques}

Les producteurs enquêtés dans la zone d'étude sont constitués de $85,60 \%$ d'hommes et $14,40 \%$ de femmes âgés de 20 à 76 ans (Figure 2). L'âge moyen des producteurs est de 44 ans. Ils ont en moyenne 21 ans d'expérience dans la culture de la patate douce et sont en majorité analphabètes $(73,06 \%)$. La plupart des producteurs enquêtés $(81,69 \%)$ cultivent la patate douce sur de petites superficies pouvant atteindre 0,8 ha contre $18,31 \%$ qui la cultivent sur de grandes superficies allant de 1 à 4 ha. La majorité des producteurs enquêtés $(32,16 \%)$ appartient au groupe socioculturel Aïzo. Les autres producteurs enquêtés sont des Ouémin $(20,72 \%)$, des Fon $(18,10 \%)$, des Adja $(10,75 \%)$, des Sahouè $(7,21 \%)$, des Holli $(6,52 \%)$ et des Nagot (4,53\%). Selon 26,38\% de ces producteurs, la patate douce est la $3^{\text {ème }}$ production en termes de production de culture mais pour respectivement $24,43 \% ; 17,10 \%$ et $9,94 \%$ d'eux, elle est classée au 4ème, $2^{\text {ème }}$ et $1 \mathrm{er}$ rang. En dehors de ces rangs, $22,15 \%$ des producteurs classe la patate douce au $5^{\text {ème }}$ et $6^{\text {ème }}$ rang. Les raisons qui motivent la production de patate douce sont la commercialisation sur les marchés locaux et régionaux $(67,33 \%)$ et l'autoconsommation $(32,67 \%)$.

\section{Variabilité de la diversité de la patate douce au Sud du Bénin}

Sous réserve de synonymie, 87 variétés locales ont été recensés à travers les 35 villages prospectés. Le cycle de reproduction de ces différentes variétés varie de deux mois et demi à six mois. La culture de patate douce se fait majoritairement sur des billons $(70 \%$ des cas) et minoritairement sur des buttes (30\%). Le Tableau 2 présente la variation du nombre de cultivars par département. Le nombre total de variétés locales utilisées varie de 12 pour l'Ouémé à 3 pour le Plateau. Les résultats d'analyse de variance portant sur la richesse en variétés montrent une différence significative entre le nombre de variétés par commune au sein d'un département. Le nombre moyen de variétés locales est 4,62 \pm 2,64 pour la zone d'étude. Ce nombre est plus élevé $(8 \pm 3,03)$ dans l'Ouémé et plus faible $(2,8 \pm 0,83)$ dans le Plateau. Le nombre de variétés locales par commune varie de 2 à 14 . Les communes de Ouinhi, d'Adjohoun et d'Abomey Calavi ont les plus grands nombres avec respectivement $14 ; 12$; et 11 (Figure 3). Les communes de Bopa, de Pobè et de Toviklin présentent les plus faibles nombres (2). De même, il a été observé une variation du nombre de variétés locales par village surtout dans les communes où la diversité est élevée (Tableau 3). La plus forte diversité par village a été observée dans les villages de Glédjiaga et Sissèkpa dans la commune de Adjohoun et Sokan dans la commune d'Abomey-Calavi avec respectivement $12 ; 11$ et 9 cultivars. Par contre, il a été observé que dans la commune de Ouinhi qui présente le plus grand nombre de variétés locales, la diversité par village est faible comparativement aux communes de Adjohoun et d'Abomey-Calavi. C'est dans le village de Aïzè Zokpodji dans la commune de Ouinhi qu'on dénombre le grand nombre de variétés (7) (Tableau 4). Certaines variétés locales comme «Vobodouaho », «Mètché » se 
retrouve dans plusieurs villages dans la zone prospectée avec des fréquences respectivement de $54,42 \% ; 28,57 \%$. Ce qui montre qu'ils ont une large distribution. Par contre d'autres comme «Blè », "Gbomakan » sont faiblement représentés dans la zone d'étude avec des fréquences respectivement de $2,85 \%$ et $5,71 \%$ (Figure 4 ). Les causes de la variation de la fréquence de distribution des variétés sont l'abandon suivi de la disparition de certaines variétés locales au détriment d'autres. Les raisons de cette disparition sont nombreuses (Figure 5). On peut citer des raisons agronomiques et économiques. Parmi les raisons agronomiques, les plus importantes sont l'introduction de nouvelles variétés plus performantes en terme de productivité ( $20,73 \%$ des réponses), le cycle de culture long de certaines variétés $(17,19 \%$ des réponses), des variétés inadaptées au sol $(15,55 \%)$, la baisse de la productivité $(13,65 \%)$, la sécheresse $(12,89 \%)$, la non disponibilité des semences $(9,1 \%)$ et la sensibilité aux attaques parasitaires (4,04\%). $\mathrm{La}$ faible valeur marchande, constitue aussi une raison économique non négligeable $(6,82 \%$ des réponses).

\section{Critères clés de reconnaissance des variétés locales par les producteurs}

Au sud du Bénin, les critères utilisés par les producteurs pour distinguer les différentes variétés locales de la patate douce sont basés sur sept (7) paramètres morphologiques (Tableau 4). La couleur de la peau des tubercules (CPeT), la couleur de la pulpe des tubercules (CPuT), la couleur de la tige (CTi), la forme des feuilles ( $\mathrm{FFe}$ ), la couleur de la feuille $(\mathrm{CFe})$, la longueur de la tige (LTi), la forme des tubercules (FT) sont couramment utilisés comme critères. L'analyse de la variation des critères au sein de chaque groupe socio-culturel a montré que la couleur de la peau des tubercules, la couleur de la pulpe des tubercules, la forme et la couleur des feuilles sont les critères plus utilisés par tous les groupes socio-culturels pour reconnaître les variétés locales de patate douce. Il existe une différence hautement significative entre les groupes socio-culturels par rapport à la couleur de la tige, la longueur de la tige et la forme des tubercules. Ainsi donc, l'identification des variétés locales sur la base de ces critères varie entre les groupes socio-culturels. De même, au sein des groupes socio-culturels Ouémin, Aïzo et Fon, il existe une différence hautement significative par rapport aux critères de reconnaissance de ces variétés. Ceci signifie qu'au sein même des individus du même groupe, il existe une variation par rapport aux critères utilisés pour la reconnaissance des variétés locales. Les caractéristiques de quelques variétés locales identifiées sur la base de quatre (4) paramètres morphologiques par les producteurs sont résumées dans le Tableau 5.

\section{Critères de préférence des variétés locales par les producteurs}

Dans la zone d'étude, douze (12) critères de préférences d'ordre agromorphologique $(68,54 \%)$, économique $(16,13 \%)$ et culinaire $(15,32 \%)$ ont été identifiés. De ses critères, huit (8) sont d'ordre agro-morphologique et constitue les critères les plus importants. Parmi les critères agromorphologiques, on peut citer la précocité $(15,07 \%)$, le fort taux de multiplication $(19,32 \%)$, la tolérance à la sécheresse $(5,26 \%)$, la résistance aux maladies et parasites $(3,14 \%)$, la tolérance aux mauvaises herbes $(1,42 \%)$, l'adaptabilité au sol $(9,96 \%)$, la bonne conservation post-récolte $(7,74 \%)$ et la couleur des tubercules $(6,63 \%)$. Le critère valeur marchande élevée $(16,13 \%)$ constitue l'unique critère économique. La bonne qualité des tubercules bouillis $(3,64 \%)$, la bonne qualité des tubercules frits $(4,90 \%)$ et le bon goût $(6,78 \%)$ sont les trois critères culinaires énumérés par les producteurs de la zone d'étude (Tableau 6). Parmi ces critères, et d'une façon générale la précocité, le fort taux de multiplication, l'adaptabilité au sol, la bonne conservation post-récolte, la valeur marchande élevée sont les critères de préférences les plus importantes pour la 
majorité des groupes socio-ethniques. Cependant, il a été observé une variation de l'importance de ces critères d'un groupe socio-culturel à un autre. La couleur des tubercules, intéresse particulièrement les Aïzo (tableau 6). Chez les Ouémin, en dehors de la couleur des tubercules, la tolérance à la sécheresse constitue un critère de préférence surtout pour les producteurs qui réalisent leur culture sur la terre ferme car d'autres producteurs réalisent la culture dans les basfonds. Il est à signaler aussi que les Sahouè et les Adja préfèrent les variétés à peau rouge. Les variétés à peau blanche présentent plutôt un intérêt cultuel pour ces dernières.

\section{Contraintes liées à la production de la patate douce}

$\mathrm{Au}$ total, sept (7) contraintes majeures handicapent la production de la patate douce au sud du Bénin avec une prédominance de l'insuffisance des boutures ou lianes de variétés performantes $(19,73 \%)$. Elle est suivie de la rareté des pluies $(19,46 \%)$, la baisse de la productivité $(18,10 \%)$, les ravageurs et maladies $(15,56 \%)$, la pauvreté $\mathrm{du}$ sol $(14,30 \%)$, les difficultés liées à la conservation post-récolte $(9,14 \%)$ et les mauvais herbes $(3,75 \%)$. Ces contraintes dépendent très significativement des départements $\left(\chi^{2}=190,03\right.$ et $\left.p=0\right)$. Ainsi, il a été observé une forte variation de l'ordre de ces contraintes suivant les départements. Les contraintes concernant l'insuffisance de boutures ou de lianes de variétés performantes, la rareté des pluies et la pauvreté du sol sont communes à tous les départements. Cependant, des spécificités ont été observées en fonction des départements. Dans les départements du Couffo et du Mono, les difficultés liées à la conservation postrécolte constituent en plus des autres contraintes, un facteur majeur qui ralentit la production de la patate douce. Par contre, dans l'Ouémé, l'Atlantique et le Zou, les ravageurs et maladies constituent une contrainte majeure qui leur est spécifique. Dans le Zou et le plateau et en partie l'Atlantique, on note aussi que la baisse de la productivité observée au niveau de certaines variétés locales est aussi un facteur qui limite la production (Tableau 7).

\section{Pratiques agricoles sur la conservation des tubercules}

Pour la plupart des producteurs de toute la zone de production, la conservation des tubercules de patate douce constitue un problème. En effet, la patate douce n'est pas conservable sur une longue durée. Cependant, on distingue trois techniques traditionnelles de conservation à courte durée des tubercules :

Conservation sur billons ou buttes : elle est réalisée par $59,27 \%$ des producteurs. Cette technique de conservation s'observe surtout chez les producteurs qui font la culture sur des terres fermes où il n'existe pas de risque d'inondation. Les producteurs ne récoltent pas les tubercules arrivés à maturité et les laissent sur les buttes ou billons jusqu'à la vente. Cette technique ne s'applique pas à toutes les variétés car certaines, une fois arrivée à maturité, sont très attaquables par les ravageurs dont les insectes. La variété locale «Bombo vèvè " (à tubercules rouges) peut ainsi rester sur billons pendant deux à trois semaines sans être attaqués. Par contre, la variété «Mêtché » n'est pas conservable car sa peau est fragile et très sensible aux ravageurs.

Conservation dans un endroit humide: elle est pratiquée par $30,78 \%$ des producteurs de la zone d'étude. Dans ce cas, les tubercules récoltés sont mis en tas dans un endroit frais à l'abri de la lumière pendant environ quinze à vingt-huit (15 à 28) jours. Les tubercules peuvent être recouverts par des herbes ou non puis on arrose légèrement le tas. Pour les producteurs qui pratiquent ce mode de conservation, l'inconvénient est la pourriture des tubercules due à la chaleur qui se dégage de l'intérieur du tas.

Conservation dans des trous : seuls 9,94\% des producteurs enquêtés pratiquent la technique de conservation dans des trous. En effet, ces derniers creusent des trous au champ, mettent des herbes, puis déposent les 
tubercules à l'intérieur. Ensuite, ils recouvrent les tubercules avec des herbes, avant d'ajouter la terre en surface.

\section{Pratiques agricoles de gestion des semences de patate douce}

Les boutures de tiges ou lianes des différentes variétés locales constituent le matériel de plantation de la patate douce. L'obtention de ces boutures pour la production se fait suivant plusieurs techniques par les producteurs et résumées par la Figure 6 . Pendant la saison des pluies, on observe une repousse des lianes ou boutures à partir des fragments de tubercules laissés dans le sol après la récolte. De même, certains producteurs réalisent des pépinières des cultivars de patate douce à partir des boutures de la saison précédente ou des tubercules issus de ces cultivars. D'autres producteurs procèdent à l'achat de lianes ou tubercules auprès des producteurs. Aussi, il faut signaler que, dans les zones de bas-fonds, les boutures des différentes variétés locales sont souvent disponibles. Ce qui permet des échanges de matériel de plantation entre ces producteurs.

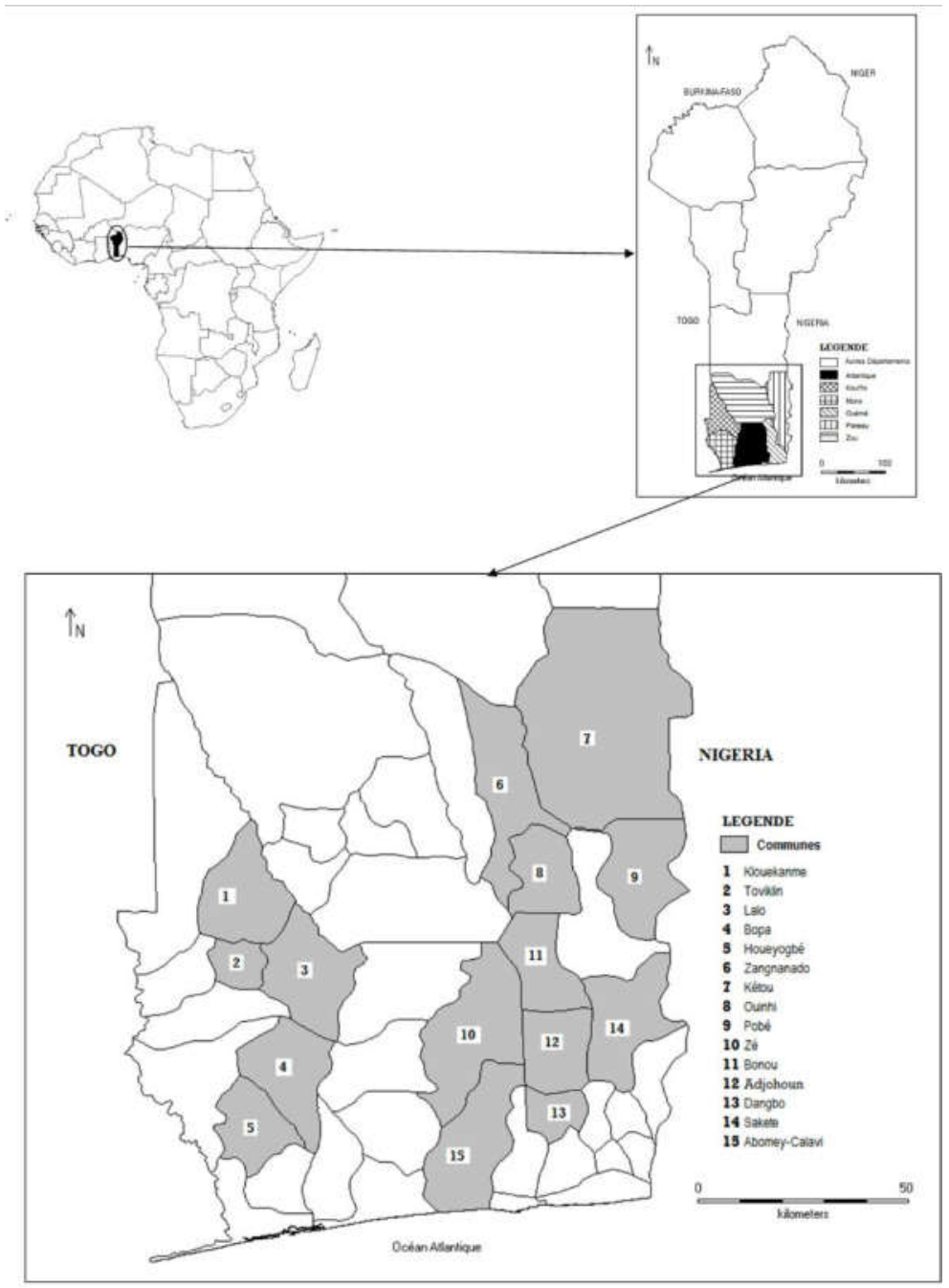

Figure 1 : Zone d'étude. 


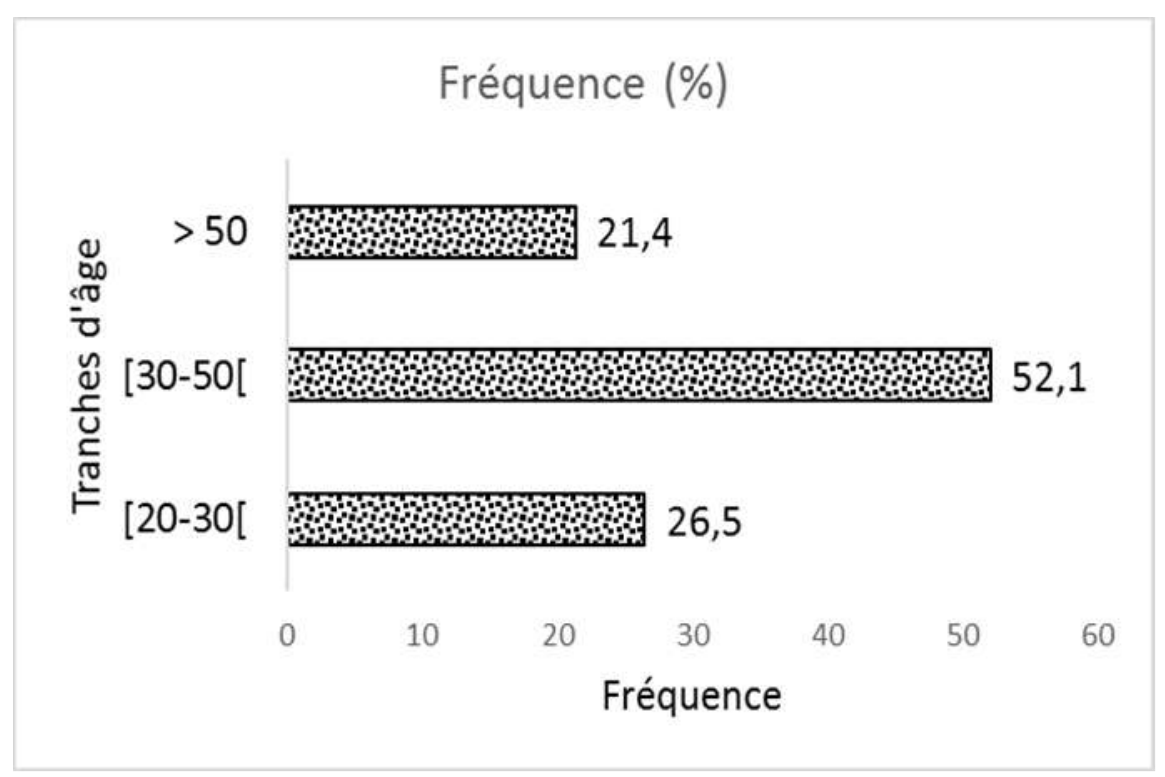

Figure 2 : Répartition des enquêtés en âge.

Tableau 1 : Liste des villages prospectés.

\begin{tabular}{llll}
\hline Numéro & Villages & Communes & Groupes socio-culturels \\
\hline $\mathbf{1}$ & Adjogansa & Abomey-calavi & Aïzo \\
$\mathbf{2}$ & Agbanta & Dangbo & Ouémin \\
$\mathbf{3}$ & Agbossoukota & Bonou & Ouémin \\
$\mathbf{4}$ & Agongoh & Bopa & Sahouè \\
$\mathbf{5}$ & Aïzè Zokpodji & Ouinhi & Fon \\
$\mathbf{6}$ & Awokpa & Zè & Aïzo \\
$\mathbf{7}$ & Ayita & Sakété & Nago \\
$\mathbf{8}$ & Danhoué & Houéyogbé & Sahouè \\
$\mathbf{9}$ & Dèkin & Dangbo & Ouémin \\
$\mathbf{1 0}$ & Dodji & Houéyogbé & Sahouè \\
$\mathbf{1 1}$ & Dokota & Zè & Aïzo \\
$\mathbf{1 2}$ & Gbèdogogléta & Adjohoun & Ouémin \\
$\mathbf{1 3}$ & Gbodjè & Abomey -calavi & Aïzo \\
$\mathbf{1 4}$ & Gbodjoko & Abomey-calavi & Aïzo \\
$\mathbf{1 5}$ & Gladji & Abomey-calavi & Aïzo \\
$\mathbf{1 6}$ & Glédjiaga & Adjohoun & Ouémin \\
$\mathbf{1 7}$ & Glo Fanto & Abomey-Calavi & Aïzo \\
$\mathbf{1 8}$ & Gnanmanmè & Lalo & Adja \\
$\mathbf{1 9}$ & Hadjanaho & Abomey-Calavi & Aïzo \\
$\mathbf{2 0}$ & Houndji centre & Klouékanmè & Adja \\
$\mathbf{2 1}$ & Kaïhoué & Lalo & Adja \\
$\mathbf{2 2}$ & Kpoto & Zagnanado & Fon \\
$\mathbf{2 3}$ & Odomèta & Kétou & Holli \\
$\mathbf{2 4}$ & Onigbolo & Pobè & Nago \\
$\mathbf{2 5}$ & Ouédja & Ouinhi & Fon \\
$\mathbf{2 6}$ & Sissèkpa & Adjohoun & Ouémin \\
$\mathbf{2 7}$ & Sokan & Abomey-Calavi & Aïzo \\
\hline
\end{tabular}




\begin{tabular}{llll}
$\mathbf{2 8}$ & Takou & Kétou & Holli \\
$\mathbf{2 9}$ & Tohon & Houéyogbé & Sahouè \\
$\mathbf{3 0}$ & Toviklin centre & Toviklin & Adja \\
$\mathbf{3 1}$ & Wédjamè & Zè & Aïzo \\
$\mathbf{3 2}$ & Yobohoué & Lalo & Adja \\
$\mathbf{3 3}$ & Zonmon Kousso & Ouinhi & Fon \\
$\mathbf{3 4}$ & Zoungo & Ouinhi & Fon \\
$\mathbf{3 5}$ & Zounkpè -Etigbo & Kétou & Fon \\
\hline
\end{tabular}

Tableau 2 : Variation du nombre de variétés locales par département dans la zone prospectée.

\begin{tabular}{ccccc}
\hline Départements & $\begin{array}{c}\text { Nombre de } \\
\text { village }\end{array}$ & $\begin{array}{c}\text { Nombre } \\
\text { minimum de } \\
\text { variétés locales }\end{array}$ & $\begin{array}{c}\text { Nombre } \\
\text { maximum de } \\
\text { variétés locales }\end{array}$ & $\begin{array}{l}\text { Richesse } \\
\text { moyenne en } \\
\text { variétés locales }\end{array}$ \\
\hline Atlantique & 10 & 2 & 9 & $4,8 \pm 2,65$ \\
Couffo & 5 & 2 & 4 & $3 \pm 0,70$ \\
Mono & 4 & 2 & 5 & $3,2 \pm 1,25$ \\
Ouémé & 6 & 4 & 12 & $8 \pm 3,03$ \\
Plateau & 5 & 2 & 3 & $2,8 \pm 0,83$ \\
Zou & 5 & 3 & 7 & $4,8 \pm 1,78$ \\
Zone d'étude & $\mathbf{3 5}$ & $\mathbf{2}$ & $\mathbf{1 2}$ & $\mathbf{4 , 6 2} \pm \mathbf{2 , 6 4}$ \\
\hline
\end{tabular}

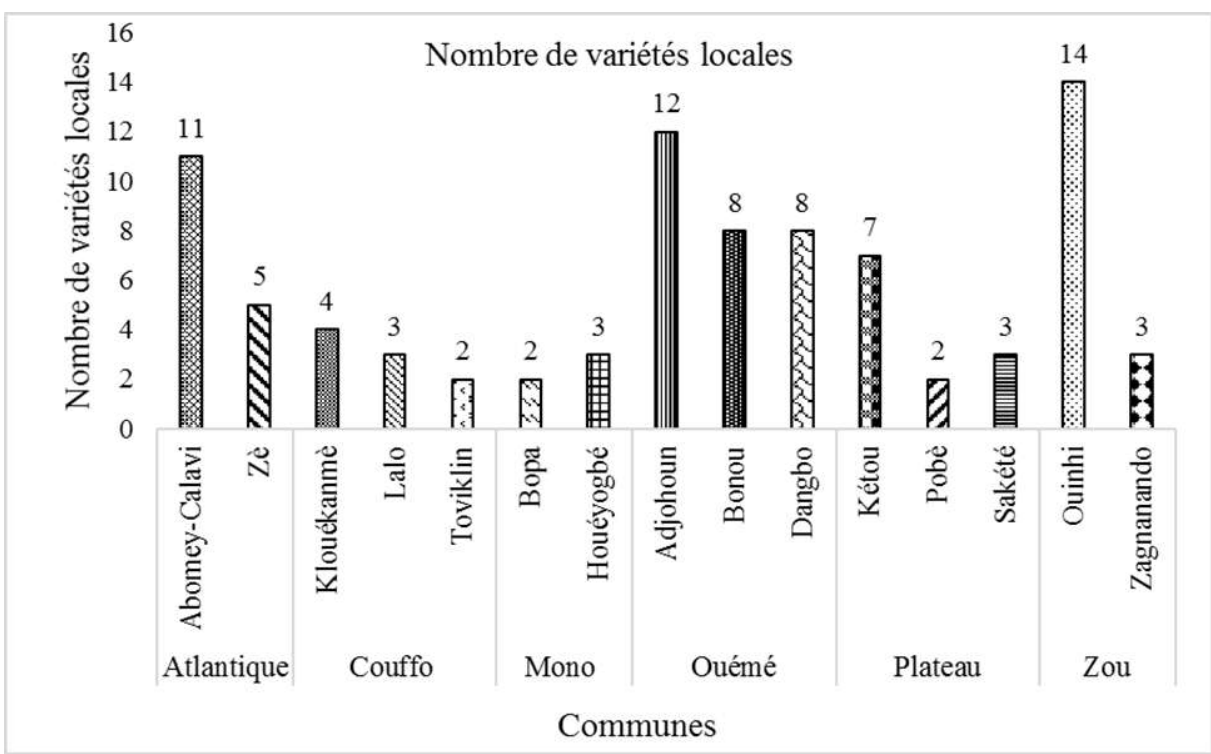

Figure 3 : Variation du nombre de variétés locales dans les communes prospectées.

Tableau 3 : Variation de la diversité des variétés locales par village au Sud Bénin.

\begin{tabular}{lcrrlcrc}
\hline Villages & $\begin{array}{l}\text { Nombre de } \\
\text { variétés }\end{array}$ & Min & Max & Villages & $\begin{array}{l}\text { Nombre de } \\
\text { variétés }\end{array}$ & Min & Max \\
\hline $\begin{array}{l}\text { Adjogansa } \\
\text { Agbanta }\end{array}$ & 8 & 3 & 5 & Hadjanaho & 4 & 1 & $\mathbf{4}$ \\
\hline
\end{tabular}


A. M. DOUSSOH et al. / Int. J. Biol. Chem. Sci. 10(6): 2596-2616, 2016

\begin{tabular}{llllllll}
\hline Agbossoukota & 8 & 2 & 8 & Kä̈houé & 3 & 1 & $\mathbf{3}$ \\
Agongoh & 2 & 1 & 2 & Kpoto & 3 & 1 & $\mathbf{3}$ \\
Ä̈zè Zokpodji & 7 & 2 & 5 & Odomèta & 2 & 1 & $\mathbf{2}$ \\
Awokpa & 2 & 1 & 2 & Onigbolo & 2 & 1 & $\mathbf{2}$ \\
Ayita & 3 & 1 & 3 & Ouédja & 6 & 1 & $\mathbf{4}$ \\
Danhoué & 3 & 1 & 3 & Sissèkpa & 1 & 3 & $\mathbf{5}$ \\
Dèkin & 7 & 2 & 4 & Sokan & 9 & 3 & $\mathbf{6}$ \\
Dodji & 5 & 2 & 5 & Takou & 3 & 2 & $\mathbf{3}$ \\
Dokota & 3 & 2 & 3 & Tohon & 3 & 1 & $\mathbf{3}$ \\
Gbèdogogléta & 4 & 1 & 4 & Toviklin centre & 2 & 1 & $\mathbf{2}$ \\
Gbodjè & 2 & 1 & 2 & Wédjamè & 3 & 1 & $\mathbf{3}$ \\
Gbodjoko & 7 & 3 & 5 & Yobohoué & 3 & 1 & $\mathbf{3}$ \\
Gladji & 3 & 1 & 3 & Zonmon Kousso & 5 & 1 & $\mathbf{4}$ \\
Glédjiaga & 1 & 3 & 6 & Zoungo & 3 & 1 & $\mathbf{3}$ \\
Glo Fanto & 7 & 2 & 5 & Zounkpè-Etigbo & 4 & 2 & $\mathbf{4}$ \\
Gnanmanmè & $\mathbf{3}$ & $\mathbf{1}$ & $\mathbf{3}$ & & & & \\
\hline
\end{tabular}

Tableau 4 : Critères de reconnaissance des variétés locales par les producteurs.

\begin{tabular}{|c|c|c|c|c|c|c|c|c|c|}
\hline $\begin{array}{c}\text { Traits de } \\
\text { reconnaissance } \\
\text { Groupes socio- } \\
\text { culturels }\end{array}$ & CPeT (\%) & CPuT (\%) & CTit(\%) & $\operatorname{FFe}(\%)$ & CFe $(\%)$ & LTi(\%) & FT (\%) & Chi 2 & 1-p \\
\hline Quémin & 100 & 35,5 & 71,0 & 90,3 & 35,5 & 3,2 & 3,2 & 26,77 & $99,98^{* * 8}$ \\
\hline Ä̈zo & 99,0 & 60,2 & 14,3 & 82,7 & 28,6 & 20,4 & 21,4 & 11,86 & $93,49 * * 8$ \\
\hline Sahouè & 100 & 31,6 & 10,5 & 89,5 & 10,5 & 0 & 0 & 8,82 & $81,61^{* *}$ \\
\hline Nago & 100 & 44,4 & 22,2 & 66,7 & 33,3 & 0 & 0 & 2,80 & $16,66 \mathrm{~ns}$ \\
\hline Adja & 100 & 50,0 & 10,0 & 60,0 & 20,0 & 0 & 0 & 10,03 & $87,67^{* *}$ \\
\hline Fon & 95,2 & 46,8 & 22,6 & 87,1 & 24,2 & 41,9 & 1,6 & 15,55 & $98,36^{* * 8}$ \\
\hline Holi & 100 & 62,5 & 25,0 & 37,5 & 25,0 & 0 & 0 & 4,18 & $34,77 \mathrm{~ns}$ \\
\hline Chi 2 & 3,40 & 4,75 & 26,71 & 2,49 & 1,98 & 29,06 & 23,61 & - & - \\
\hline 1-p & $24,26 \mathrm{~ns}$ & $42,38 \mathrm{~ns}$ & $99,98^{* * *}$ & $13,09 \mathrm{~ns}$ & $7,86 \mathrm{~ns}$ & $99,99 * * *$ & $99,94^{* * *}$ & - & - \\
\hline
\end{tabular}




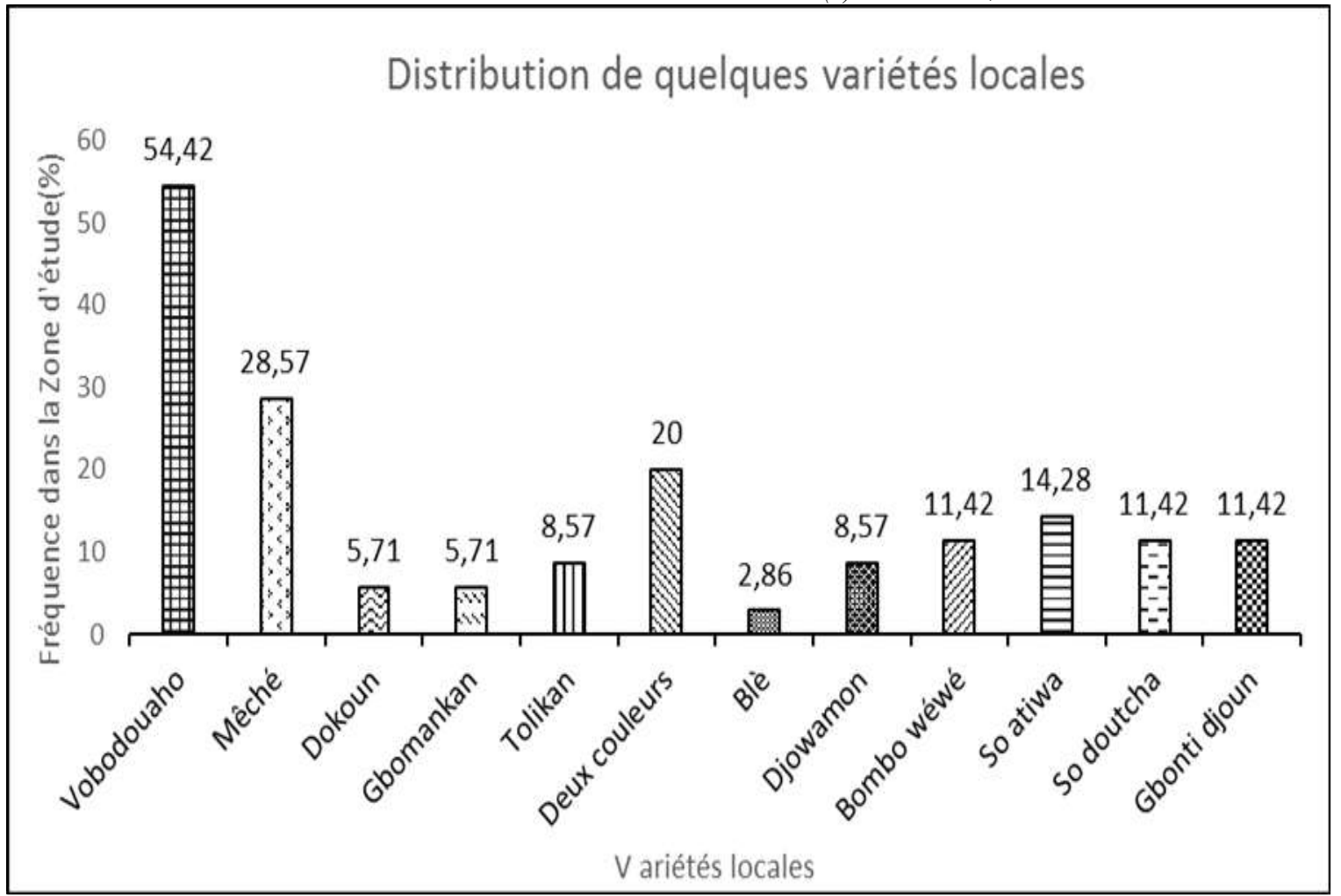

Figure 4 : Fréquence de distribution de quelques cultivars dans la zone d'étude.

Tableau 5 : Signification et caractéristiques de quelques variétés locales de patate douce.

\begin{tabular}{|c|c|c|c|c|c|c|}
\hline \multirow[b]{2}{*}{ Variétés locales } & \multirow[b]{2}{*}{ Significations } & \multicolumn{5}{|c|}{ Caractéristique des variétés locales } \\
\hline & & $\begin{array}{l}\text { Couler de } \\
\text { la peau }\end{array}$ & $\begin{array}{c}\text { Couleur de la } \\
\text { pulpe }\end{array}$ & $\begin{array}{l}\text { Forme } \\
\text { de la } \\
\text { feuille }\end{array}$ & $\begin{array}{l}\text { Longueur } \\
\text { de la tige }\end{array}$ & $\begin{array}{l}\text { Forme du } \\
\text { tubercule }\end{array}$ \\
\hline Vobodouaho & $\begin{array}{l}\text { Soit confiant et } \\
\text { endette toi } \\
\text { (précoce et bon } \\
\text { rendement) }\end{array}$ & Blanc & Blanc & Divisé & Moyen & Longue \\
\hline Mêché & $\begin{array}{l}\text { Mon ami (très bon } \\
\text { rendement) }\end{array}$ & Blanc & Blanc & Divisé & Court & Longue \\
\hline Dokoun & $\begin{array}{l}\text { Soit en train de } \\
\text { creuser (forte } \\
\text { tubérisation) }\end{array}$ & Jaune & Blanc & Uni & Court & Ronde \\
\hline $\begin{array}{l}\text { Deux couleurs } \\
\text { (amitché win) }\end{array}$ & $\begin{array}{c}\text { Présente deux } \\
\text { couleurs au } \\
\text { niveau de la } \\
\text { peau : une couleur } \\
\text { principale et une } \\
\text { secondaire. }\end{array}$ & $\begin{array}{l}\text { Pourpre } \\
\text { foncé } \\
\text { (rouge) }\end{array}$ & Jaune & Divisé & Long & Ronde \\
\hline Djowamon & $\begin{array}{c}\text { Laisser par les } \\
\text { ancêtres }\end{array}$ & Rouge & Blanc & Divisé & Moyen & Longue \\
\hline Oyou vè & Patate rouge & Rouge & Jaune & Uni & Moyen & Ronde \\
\hline
\end{tabular}




\section{Ne présente pas}

un fort

\begin{tabular}{|c|c|c|c|c|c|c|}
\hline Massawin & $\begin{array}{l}\text { développement } \\
\text { végétatif sur } \\
\text { billon avant la } \\
\text { tubérisation }\end{array}$ & Jaune & Jaune foncé & Uni & Court & Longue \\
\hline Bombo vèvè & $\begin{array}{c}\text { Produit des } \\
\text { tubercules rouge } \\
\text { gros (Bom) d'où } \\
\text { Bombo }\end{array}$ & Rouge & Jaune & Uni & Moyen & Ronde \\
\hline Bombo wéwé & $\begin{array}{c}\text { Produit des } \\
\text { tubercules blanc } \\
\text { gros (Bom) d'où } \\
\text { Bombo }\end{array}$ & Blanc & Jaune & Uni & Moyen & Ronde \\
\hline So atiwa & $\begin{array}{l}\text { Apporte ton sac } \\
\text { pour que je te } \\
\text { paye ta dette }\end{array}$ & Blanc & Blanc & Divisé & Long & Longue \\
\hline Avouzou & $\begin{array}{l}\text { Donne beaucoup } \\
\text { de feuille et peu } \\
\text { de tubercules }\end{array}$ & Blanc & Blanc & Divisé & Long & Ronde \\
\hline Atabouè & $\begin{array}{l}\text { Feuille circulaire } \\
\text { comme "ATA" }\end{array}$ & Jaune & Blanc & Uni & Moyen & Ronde \\
\hline Avoungo & $\begin{array}{c}\text { Donne des maux } \\
\text { de ventre ou } \\
\text { l'Ernie }\end{array}$ & Rouge & Blanc & Divisé & Court & Longue \\
\hline Djantro & $\begin{array}{l}\text { Développement } \\
\text { végétatif } \\
\text { vigoureux }\end{array}$ & Jaune & Blanc & Uni & Long & Longue \\
\hline doki founfoun & Patate blanche & Blanc & Blanc & Divisé & Moyen & Ronde \\
\hline Oyou wé & Patate blanche & Blanc & Jaune & Uni & Court & Longue \\
\hline Gbonti djoun & Patate rouge & Rouge & Blanc & Divisé & Long & Ronde \\
\hline So doutcha & $\begin{array}{c}\text { Produit } \\
\text { rapidement } \\
\text { (précocité) }\end{array}$ & Rouge & Blanc & Uni & Long & Longue \\
\hline $\begin{array}{l}\text { Dokouin } \\
\text { koklosin }\end{array}$ & $\begin{array}{l}\text { Patate à pulpe } \\
\text { '’jaune d'œuf", }\end{array}$ & Blanc & $\begin{array}{l}\text { Jaune/jaune } \\
\text { foncé }\end{array}$ & Divisé & Moyen & Ronde \\
\hline Gbo Ado & $\begin{array}{l}\text { Il faut avoir } \\
\text { confiance, on en } \\
\text { tire toujours un } \\
\text { rendement }\end{array}$ & Blanc & Blanc & Divisé & Moyen & Longue \\
\hline
\end{tabular}


Tableau 6 : Critères paysans de préférences des variétés locales.

\begin{tabular}{|c|c|c|c|c|c|c|c|c|c|c|c|c|}
\hline \multirow[t]{2}{*}{ Catégories } & \multirow[t]{2}{*}{ Critères } & \multicolumn{7}{|c|}{ Groupes socio-culturels } & \multirow{2}{*}{$\begin{array}{l}\text { Zone } \\
\text { d'étude } \\
(\%)\end{array}$} & \multirow[t]{2}{*}{ Chi2 } & \multirow[t]{2}{*}{ ddl } & \multirow[t]{2}{*}{$P$ value } \\
\hline & & $\begin{array}{l}\text { Adja } \\
(\%)\end{array}$ & $\begin{array}{l}\text { Aïzo } \\
(\%)\end{array}$ & $\begin{array}{l}\text { Fon } \\
(\%)\end{array}$ & $\begin{array}{l}\text { Holli } \\
(\%)\end{array}$ & $\begin{array}{l}\text { Nago } \\
(\%)\end{array}$ & $\begin{array}{l}\text { Ouémin } \\
(\%)\end{array}$ & $\begin{array}{l}\text { Sahouè } \\
(\%)\end{array}$ & & & & \\
\hline \multirow[t]{8}{*}{ Agronomiques } & Précocité & 16,59 & 14,44 & 15,82 & 9,86 & 14,28 & 16,71 & 12,03 & 15,07 & \multirow{12}{*}{159,842} & \multirow{12}{*}{66} & \multirow{12}{*}{$0,000 * * *$} \\
\hline & $\begin{array}{l}\text { Fort taux de } \\
\text { multiplication }\end{array}$ & 31,34 & 18,19 & 19,64 & 18,31 & 18,37 & 15,96 & 15,79 & 19,32 & & & \\
\hline & $\begin{array}{l}\text { Tolérante à la } \\
\text { sécheresse }\end{array}$ & 5,99 & 3,91 & 5,61 & 1,41 & 4,08 & 8.48 & 3,01 & 5,26 & & & \\
\hline & $\begin{array}{l}\text { Résistante aux } \\
\text { parasites et } \\
\text { maladies }\end{array}$ & 3,69 & 2,71 & 3,06 & 4,22 & 5,10 & 2,49 & 4,51 & 3,14 & & & \\
\hline & $\begin{array}{l}\text { Tolérante aux } \\
\text { mauvaises herbes }\end{array}$ & 1,84 & 1,35 & 3,31 & - & - & - & 1,50 & 1,42 & & & \\
\hline & Adaptabilité au sol & 2,76 & 10,52 & 11,48 & 14,08 & 6,12 & 11,97 & 9,02 & 9,96 & & & \\
\hline & $\begin{array}{l}\text { Bonne } \\
\text { conservation post- } \\
\text { récolte }\end{array}$ & 3,69 & 9,47 & 6,12 & 2,82 & 7,14 & 9,97 & 6,77 & 7,74 & & & \\
\hline & $\begin{array}{l}\text { Couleur des } \\
\text { tubercules }\end{array}$ & 5,53 & 10,52 & 3,57 & 4,22 & 6,12 & 4,24 & 6,77 & 6,63 & & & \\
\hline Economiques & $\begin{array}{l}\text { Valeur marchande } \\
\text { élevée }\end{array}$ & 13,36 & 13,68 & 17,34 & 29,58 & 26,53 & 14,96 & 18,04 & 16,13 & & & \\
\hline \multirow[t]{3}{*}{ Culinaires } & $\begin{array}{l}\text { Bonne qualité des } \\
\text { tubercules bouillis }\end{array}$ & 2,30 & 3,76 & 3,06 & 2,81 & 2,04 & 5,48 & 3,00 & 3,64 & & & \\
\hline & $\begin{array}{l}\text { Bonne qualité des } \\
\text { tubercules frits }\end{array}$ & 3,23 & 5,86 & 4,59 & 5,63 & 4,08 & 4,49 & 5,26 & 4,90 & & & \\
\hline & Bon goût & 9,68 & 5,56 & 6,37 & 7,04 & 6,12 & 5,23 & 14,28 & 6,78 & & & \\
\hline
\end{tabular}




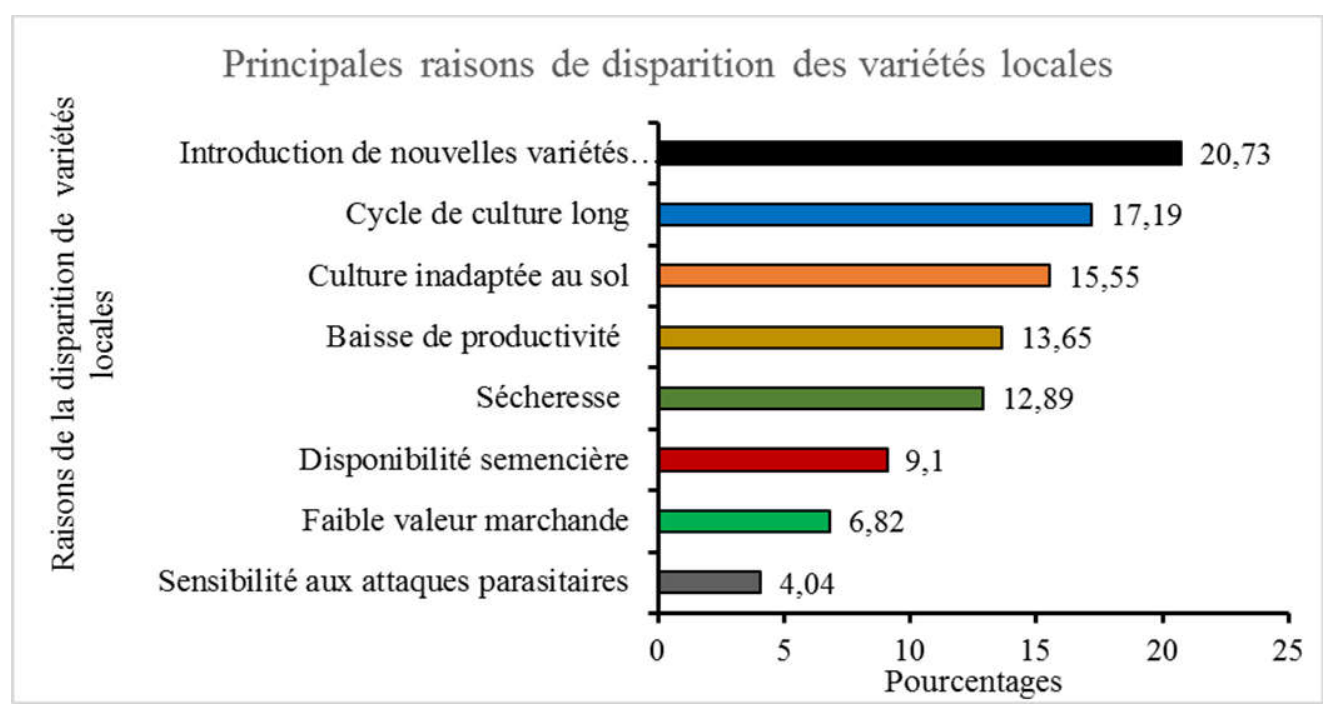

Figure 5 : Principales raisons de la disparition des variétés locales.

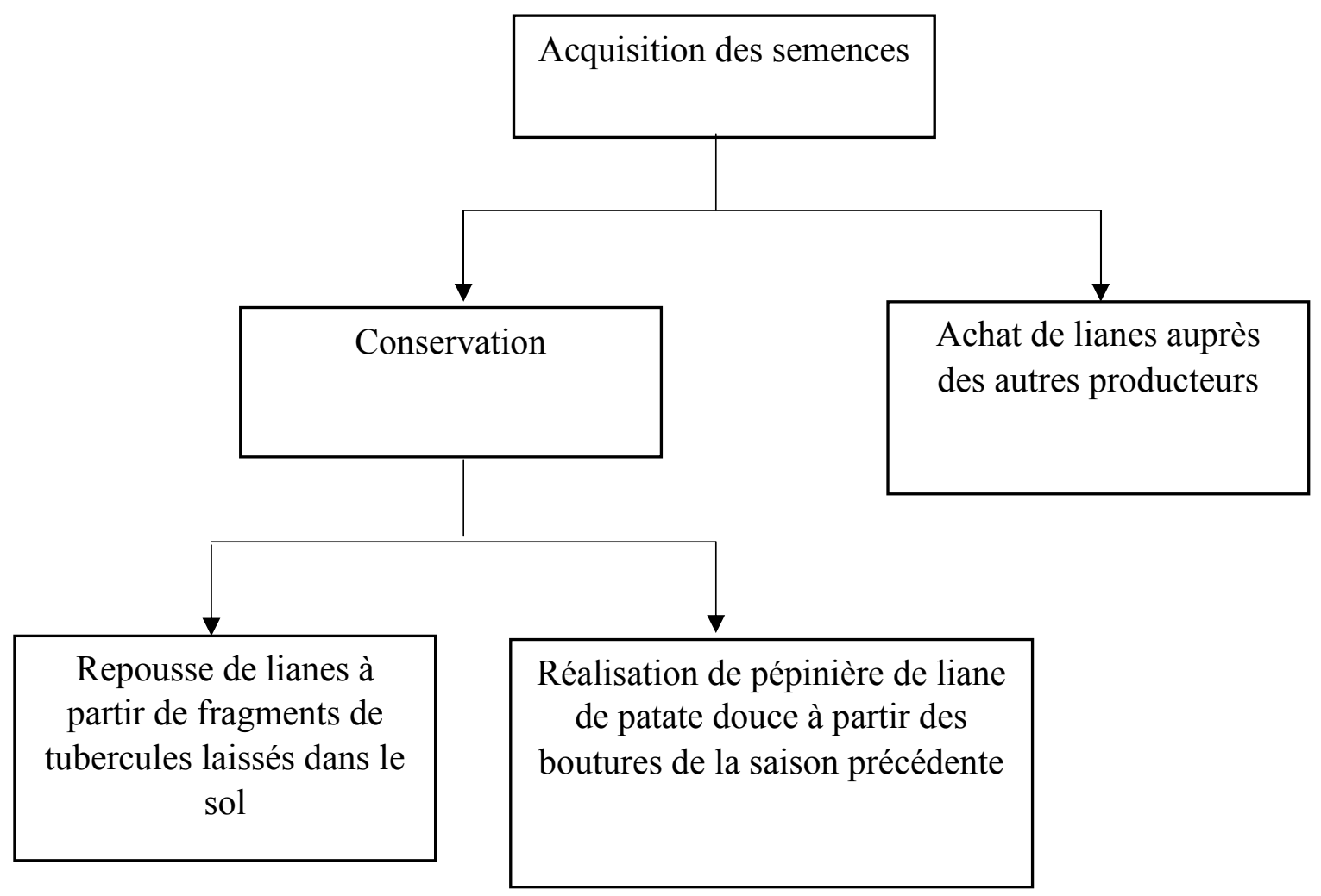

Figure 6 : Mode d'obtention des boutures destinées à la production. 
Tableau 7 : Contraintes liées à la production de la patate douce dans la zone d'étude.

\begin{tabular}{|c|c|c|c|c|c|c|c|c|c|}
\hline \multirow[t]{2}{*}{ Contraintes } & \multicolumn{6}{|c|}{ Variabilité entre départements } & \multirow{2}{*}{$\begin{array}{c}\text { Zone } \\
\text { d'études } \\
(\%)\end{array}$} & \multirow{2}{*}{$\begin{array}{l}\text { Ch } \\
\text { i } 2\end{array}$} & \multirow{2}{*}{$\begin{array}{c}P \\
\text { value }\end{array}$} \\
\hline & Atlantique & Couffo & Mono & Ouémé & Plateau & Zou & & & \\
\hline $\begin{array}{l}\text { Insuffisance } \\
\text { de boutures } \\
\text { de variétés } \\
\text { performantes }\end{array}$ & 23,33 & 14,39 & 19,13 & 29,63 & 20,89 & 10,04 & 19,73 & \multirow{7}{*}{$\begin{array}{c}19 \\
0,0 \\
3\end{array}$} & \multirow{7}{*}{$\begin{array}{l}0,000 \\
* * *\end{array}$} \\
\hline $\begin{array}{l}\text { Rareté des } \\
\text { pluies }\end{array}$ & 19,26 & 22,30 & 17,39 & 19,58 & 14,72 & 22,27 & 19,46 & & \\
\hline $\begin{array}{l}\text { Baisse de la } \\
\text { productivité }\end{array}$ & 15,56 & 10,07 & 7,82 & 13,23 & 27,60 & 28,38 & 18,10 & & \\
\hline $\begin{array}{l}\text { Ravageurs et } \\
\text { maladies }\end{array}$ & 24,81 & 9,35 & 7,82 & 19,05 & 6,13 & 16,16 & 15,56 & & \\
\hline $\begin{array}{l}\text { Pauvreté du } \\
\text { sol }\end{array}$ & 11,48 & 18,71 & 13,04 & 12,70 & 18,40 & 13,97 & 14,30 & & \\
\hline $\begin{array}{l}\text { Difficultés } \\
\text { liées à la } \\
\text { conservation } \\
\text { post- récolte }\end{array}$ & 3,70 & 20,14 & 26,09 & 2,64 & 9,20 & 5,68 & 9,14 & & \\
\hline $\begin{array}{l}\text { Mauvais } \\
\text { herbes }\end{array}$ & 1,85 & 5,03 & 8,70 & 3,17 & 3,06 & 3,49 & 3,71 & & \\
\hline
\end{tabular}




\section{DISCUSSION}

Dans la zone d'étude, il existe plusieurs variétés locales de patate douce utilisées pour la production. $\mathrm{La}$ commercialisation et l'autoconsommation constituent les raisons de production de cette culture. Ce qui montre que la patate douce peut jouer un rôle important dans la lutte contre la pauvreté par une amélioration des revenus des producteurs comme le cas du manioc et de l'igname qui sont des cultures majeures au Sud et au Centre du Bénin (Agre et al., 2015).

\section{Variabilité de la diversité de la patate douce au Sud du Bénin}

La diversité au sein des variétés locales de patate douce utilisées par chaque producteur varie d'un village à un autre, d'une commune à une autre et d'un département à un autre au sein des groupes socio-culturels. Ainsi dans les départements de l'Atlantique, de l'Ouémé et du Zou dans lesquels on retrouve les groupes socio-culturels Fon, Aïzo et Ouémin, les nombres de variétés locales recensées sont plus élevé $(14 ; 12 ; 11)$. Par contre, dans les départements du Plateau, du Mono et du Couffo regroupant les groupes socio-culturels Holli, Nago, Sahouè et Adja, le nombre de cultivars recensé est moins élevé (2). Ceci pourrait s'expliquer par le fait que ces trois départements (Atlantique, Ouémé et Zou) représentent les zones de forte production de patate douce au Bénin. Ce qui favorise des échanges de matériel de plantation d'une zone à une autre. Selon Adégbola (2003), la production de patate douce dans les départements de l'Ouémé et de l'Atlantique représentait plus de $50 \%$ de la production nationale. Par ailleurs, les résultats sur la distribution de quelques variétés ont montré que les variétés locales «Vobodouaho », « Mètché » identifiées comme élites par les producteurs sont très cultivés et présentent une large distribution dans la zone d'étude comparativement aux cultivars «Blè », "Gbomakan» qui ne se retrouvent qu'à l'échelle d'un ou de deux villages avec une très faible fréquence de production et sont donc en voie de disparition. Ces variétés locales méritent par conséquent une attention particulière de conservation $e x$ situ (in vitro) pour les préserver d'une perte définitive comme l'a souligné Harouna et al. (2015) sur la patate douce au Niger. C'est le cas pour le manioc (Cacaï et al., 2012), l'igname (Ahanhanzo et al., 2012) au Bénin.

\section{Critères de reconnaissance et de préférences paysans}

Les producteurs se basent sur des traits morphologiques pour identifier les variétés locales de patate douce. Ainsi, les feuilles à travers leurs formes et leurs couleurs, les tiges à travers leurs couleurs et leurs longueurs et les tubercules à travers la couleur de leur peau et de leur pulpe puis leur forme sont utilisés par ces producteurs pour reconnaitre les variétés. Les producteurs ont donc des connaissances sur les critères morphologiques de reconnaissance variétale qui méritent d'être capitalisées pour une meilleure classification des variétés. Par ailleurs, plusieurs critères sont utilisés et concourent aux choix de ces variétés. Les plus importants sont la précocité, le fort taux de multiplication, la forte valeur marchande et l'adaptation à tout type de sol. Ces résultats, tout comme ceux obtenus sur le manioc (Agre et al., 2015) montre que la précocité et le fort taux de multiplication sont essentiels pour le choix des variétés par les producteurs. Ces critères de préférence 
concourent d'ailleurs au choix des noms locaux attribués aux différentes variétés locales. Ces noms locaux varient selon les groupes socio-culturels d'un village à un autre. Ce qui présente un risque de surestimation ou de sous-estimation de la diversité existant au sein des cultivars. Ainsi, il n'est pas exclu que plusieurs variétés locales génétiquement différents soient désignés par le même nom ou que la même variété soit désignée par plusieurs noms comme l'ont souligné plusieurs auteurs sur la patate douce (Ndirigwe et al., 2005), le manioc (Njukwe et al., 2013). La caractérisation agro morphologique et la caractérisation génétique moléculaire sont nécessaires afin de clarifier les synonymies et d'établir les différences ou les ressemblances entre les noms locaux. Ce fut le cas pour la patate douce au Burkina Faso (Koussao et al., 2014), le mil (Dagba et al., 2015) et le sorgho (Missihoun et al., 2015) au Bénin.

\section{Contraintes liées à la production de la patate douce}

La culture de la patate douce est confrontée à de multiples contraintes biotiques et abiotiques. Les contraintes biotiques d'ordre agronomique les plus importantes observées sont l'insuffisance de variétés locales performantes, la baisse de la productivité, les ravageurs et maladies. La rareté des pluies représente également une contrainte abiotique majeure qui ne semble épargner aucune région du Bénin (DossouAminon et al., 2014). Ces différentes contraintes peuvent être surmontées par la sélection et l'utilisation de cultivars locaux plus performants en terme de tolérance à la sécheresse, de résistance aux ravageurs et maladies et de productivité comme pour certaines cultures dont le manioc (Agre et al., 2015). De même, les techniques de culture in vitro à travers la micropropagation peuvent être utiliser pour multiplier ces variétés sélectionnées comme ce fut le cas pour le manioc (Cacaï et al., 2012), le bananier (Gandonou et al., 2012).

\section{Pratiques agricoles sur la conservation des tubercules et la gestion des semences de patate douce}

Les techniques traditionnelles $\mathrm{de}$ conservation des tubercules utilisées au Bénin (la conservation sur billons, la conservation dans un endroit humide et dans une très moindre mesure la conservation dans un trou) ne permettent de conserver les tubercules que pendant quelques semaines ( 2 à 4 semaines au maximum en fonction des variétés). Ces techniques ressemblent à celles utilisées au Niger et décrites par Harouna et al. (2015) (Stockage à l'ombre des arbres, la conservation sur pied, conservation dans des greniers). Les dégâts les plus souvent observés sont la pourriture des tubercules liée soit à l'humidité relativement élevée, soit à l'attaque des ravageurs post-récoltes. Ces dégâts pourront être expliqués par la température qui est largement au-dessus de la moyenne requise pour la conservation qui est de $16{ }^{\circ} \mathrm{C}$ et la non maîtrise de l'humidité. Il est donc nécessaire d'améliorer ces techniques comme ce fut le cas dans les pays de l'Afrique de l'Est dont le Zimbabwé où les tubercules récoltés sont mélangés à la poudre de cendre (Mutandwa et al., 2007). En effet, selon ces auteurs, la cendre absorbe l'humidité et a un effet répulsif sur les ravageurs.

En ce qui concerne le système semencier au Bénin, les investigations montrent qu'il est purement traditionnel et 
reste informel, non structuré comparativement à ceux d'autres pays de l'Afrique comme le Burkina-Faso, le Rwanda, l'Ouganda où il a été observé la présence de structures spécialisées dans la production et la distribution de semences améliorés de patate douce (Gibson et al., 2009). Ces modes traditionnels de production ou d'acquisition de semences reviennent moins chers aux producteurs. Cependant, les semences sont de faibles qualités phytosanitaires et occasionnent la propagation des maladies virales et bactériennes (Ngailo et al., 2013). Les techniques de culture in vitro pourraient être mises à contribution pour améliorer la qualité et la disponibilité semencière de la patate douce à l'instar d'autres plantes à racines et tubercules au Bénin (Cacaï et al., 2012).

\section{Conclusion}

Cette étude a permis de recenser 87 variétés locales au Sud du Bénin. Pour reconnaître les différentes variétés, les producteurs utilisent sept (7) critères agronomiques alors que la préférence de l'une ou l'autre de ces variétés est basée sur douze (12) critères agromorphologiques, culinaires et économiques. La production de la patate douce est confrontée à de nombreuses contraintes biologiques. Par ailleurs, les méthodes de conservation des tubercules sont traditionnelles et peu efficaces entrainant des pertes post-récoltes. De même que le système semencier utilisé est traditionnel et non structuré. Une meilleure valorisation de cette culture est donc indispensable à travers le développement de programme de sélection et d'amélioration variétale. Une caractérisation agromorphologique et génétique moléculaire est nécessaire pour évaluer la diversité au sein de cette espèce.

\section{CONFLIT D'INTERETS}

Les auteurs déclarent qu'il n'existe aucun conflit d'intérêts entre eux.

\section{CONTRIBUTIONS DES AUTEURS}

Ce travail a été réalisé en collaboration avec tous les auteurs. DMA a conçu le protocole de l'étude, réalisé les travaux de terrain, recueilli les données brutes et écrit le premier projet du manuscrit avec l'appui de AK. HS a réalisé les analyses statistiques des données. DSJ et AC ont supervisé la réalisation de ce travail et la rédaction du projet final du manuscrit. Tous les auteurs ont lu et approuvé le manuscrit final corrigé.

\section{REMERCIEMENTS}

Nos sincères remerciements aux Docteurs MISSIHOUN Antoine, CACAÏ Gilles, DAGBA Rollande du Département de Génétique et des Biotechnologies de la Faculté des Sciences et Techniques de l'Université d'Abomey-Calavi pour avoir amélioré le manuscrit de cet article. Nous remercions aussi les chefs villages, les agents d'encadrements des Secteurs Communaux de Développement Agricole et les producteurs pour leur franche collaboration dans la réalisation de ce travail.

\section{REFERENCES}

Adégbloba PY. 2003. Analyse de la filière patate douce au Bénin. PDRT/MAEP, Rapport final, $162 \mathrm{p}$.

Agre p, Kouchade S, Odjo T, Dansi M, Nzobadila B, Assogba P, Dansi A, Akoegninou A, Sanni A. 2015. Diversité et évaluation participative des cultivars 
$\mathrm{du}$ manioc (Manihot esculenta Crantz) au centre Bénin. International Journal of Biological and Chemical Sciences, 9(1): 388-408.

Ahanhanzo C, Agbidinoukoun A, Agbangla C, Adjanahoun A, Kumulungui B, Ondo Ovono P, Ndong Nzang R. Souza P. 2012. Capacité morphogénétique de quelques accessions d'ignames du complexe Dioscorea cayenensis/D. rotundata cultivées au Bénin et évaluation de la qualité du materiel régénéré. Revue Ivoirienne des Sciences et Technologie, 20: 68-86.

Akoègninou A, Van Der Burg WJ, Van Der Maesen LJG, Adjakidjè V, Essou JP, Sinsin B, Yedomonhan H. 2006. Flore Analytique du Bénin. Backuys Publishers: Cotonou \& Wageningen; $1034 \mathrm{p}$.

Cacaï GH, Ahanhanzo C, Dangou SJ, Houédjissin S, Agbangla C. 2012. Effets de différentes combinaisons hormonales sur l'organogenèse in vitro de quelques cultivars locaux et variétés améliorées de Manihot esculenta Crantz (maniocEuphorbiaceae) cultivées au Bénin. International Journal of Biological and Chemical Sciences, 6(4): 1593-1607.

Dagba AR, Missihoun A, AdoukonouSagbadja H, Savi K, Ahanhanzo C, Agbangla C. 2015. Agromorphological variability of pearl millet (Pennisetum glaucun (L.) R. Br.) cultivars grown in Benin. Journal of Experimental Biology and Agricultural Sciences, 3(5): 394406.

Dansi A, Vodouhè R, Azokpota P, Yedomonhan H, Assogba P, Adjatin A, Loko Y, Dossou-Aminon I, Akpagana K. 2012. Diversity of the Neglected and
Underutilized Crop Species of Importance in Benin. The Scientific World Journal, 932-947.

Dossou-Aminon I, Loko LY, Adjatin A, Dansi A, Elangovan M, Chaudhary P, Vodouhe R, Sanni A. 2014. Diversity, genetic erosion and farmers' preference of sorghum varieties [Sorghum bicolor (L.) Moench] in North-Eastern Benin. Int. J. Curr. Microbiol. Appl Sci., 3(10): 531552.

FAO. 2013. FAO Statistical Databases. Food and agriculture organization of the United Nations. http://faostat.fao.org.

Gandonou ChB, Ahanhanzo C, Agbangla C, Agbidinoukoun A, Doussoh A, Cacaï G, Dossoukpevi R. 2012. Micropropagation in vitro de la variété locale « Aloga » du bananier plantain (Musa x paradisiaca L.) au Bénin. International Journal of Biological and Chimical Sciences, 6(3): 1102-1111.

Gibson RW, Mwanga RO, Namanda S, Jeremiah SC, Barker I. 2009. Review of sweetpotato seed systemsin East and Southern Africa. International Potato Center (CIP), Lima, Peru. Integrated Crop Management Working Paper, $58 \mathrm{p}$.

Glato K, Aïdam A, Odah K, Tozo K, AttohMensah M, Etse K. 2014. Régénération In Vitro par organogenèse directe de pousses à partir de boutures de trois cultivars de patate douce (Ipomoea batatas) originaire du Togo. European Scientific Journal, 10(27) : 276-291.

Harouna Issa A, Doumma A, Toufique Bello M. 2015. Inventaire des variétés, des methodes locales de stockage et de protection contre les ravageurs de patate douce (Ipomoea batatas) dans la bande Ouest Niger. International Journal of 
Biological and Chemical Sciences, 9(4): 1962-1971.

Khoury CK, Heider B, Castañeda-Álvarez NP, Achicanoy HA, Sosa CC, Miller RE, Scotland RW, Wood JR, Rossel G, Eserman LA, Jarret RL, Yencho GC, Bernau V, Juarez H, Sotelo S, de Haan S, Struik PC. 2015. Distributions, ex situ conservation priorities, and genetic resource potential of crop wild relatives of sweetpotato [Ipomoea batatas (L.) Lam., I. series Batatas]. Frontiers in Plant Science, 6: 251.

Koussao S, Gracen V, Asante I, Danquah E, Ouedraogo J, Tignegre J, Belem J, Vianney M. 2014. Diversity analysis of sweet potato (Ipomoea batatas [L.] Lam) germplasm from Burkina Faso using morphological and simple sequence repeats markers. African Journal of Biotechnology, 13(6): 729-742.

Lebot V, Champagne A, Malapa R, Shiley D. 2009. NIR Determination of Major Constituents in Tropical Root and Tuber Crop Flours. Journal of Agricultural and Food Chemistry, 57(22): 10539-10547.

Missihoun A, Adoukonou-Sagbadja H, Sedah P, Dagba R, Ahanhanzo C, Agbangla C. 2015. Genetic diversity of Sorghum bicolor (L.) Moench landraces from Northwestern Benin as revealed by microsatellite markers. African Journal of Biotehnology, 14(16): 1342-1353.

Mutandwa E, Gadzirayi CF. 2007. Comparative assessment of indigenous methods of Sweetpotato preservation among smallholder farmers: case of grass, ash and soil based approaches in Zinbabwe. African Studies Quarterly, 9(3): 86-98.
Ndirigwe J, Muyango S, Kapinga R, Tumwegamire S. 2005. Participatory on farm selection of sweetpotato varieties in some provinces of Rwanda. African Crop Science Conference Proceedings, 7: 1205-1209.

Ngailo S, Shimelis H, Sibiya J, Mtunda K. 2013. Sweet potato breeding for resistance to sweet potato virus disease and improved yield: progress and challenges. African Journal of Agricultural Research, 8(25): 32023215.

Njukwe E, Hana R, Kirscht H, Araki S. 2013. Farmers perception and criteria for cassava variety preference in Cameroon. African Study Monographs, 34(4): 221234.

Orobiyi A, Dansi A, Assogba P, Loko LY, Sanni A. 2013. Chili (Capsicum annuum L.) in southern Bénin: production contraints, Varietal diversity, preference criteria and participatory evaluation. International Research Journal of Agricultural Science and Soil Science, 3(4):107-120.

Owori C, Berga L, Mwanga R, Namutebi A, Kapinga R. 2007. Sweet potato Recipe Book: Sweet potato Processed Products from Eastern and Central Africa. Kampala, Uganda, 93p.

Romuald D, Anna O. 2013. Micro propagation of sweet potato (Ipomoea batatas (L.)Lam) from node explants. Acta Sci. Pol., Hortorum Cultus, 12(4): 117-127.

Sanoussi A, Dansi A, Bokossa-yaou I, Dansi M, Egounlety M, Sanni LO, Sanni. A. 2013. Formulation and biochemical characterization of sweet potato (Ipomoea batatas) based infant flours 
fortified with soybean and sorghum flours. International Journal of Current Microbiology and Applied Sciences, 2(7): 22-34.

Sanoussi AF, Dansi A, Ahissou H, Adebowale A, Sanni LO, Orobiyi A, Dansi M, Azokpota P, Sanni A. 2016. Possibilities of sweet potato [Ipomoea batatas (L.)] value chain upgrading as revealed by physico-chemical composition of ten elites landraces of Bénin. African Journal of Biotechnology, 15(13) : 481489.

Triqui ZE. 2009. Contribution à l'amélioration de la patate douce (Ipomoea batatas,(Lam)) par application des biotechnologies : Embryogénèse somatique et transformation génétique.
Thèse de Doctorat d'Etat Université Mohammed V-Agdal, Faculté des Sciences, Rabat, 143p.

Tumwegamire S, Rubaihayo R, LaBonte D, Grüneberg, Burgos G, Felde T, Carpio R, Pawelzik E, Mwanga R. 2011. Evaluation of dry matter, protein, starch, sucrose, $\beta$-carotene, iron, zinc, calcium and magnesium in East African Sweetpotato [Ipomoea batatas (L.) Lam] germplasm. Hortiscience, 46(3): 348357.

Zinsou V, Paraïso A, Thomas-Odjo A, Ahohuendo B. 2010. Identification des principaux agents pathogènes de la patate douce (Ipomoea batatas Lam) au Nord du Bénin. Annales des Sciences Agronomiques, 14(2): 241-255. 